\title{
Tales from the crypts: regulatory peptides and cytokines in gastrointestinal homeostasis and disease
}

\author{
Juanita L. Merchant \\ Division of Gastroenterology, Departments of Internal Medicine and Molecular and Integrative Physiology, University of Michigan, Ann Arbor, Michigan, USA.
}

\begin{abstract}
The gastrointestinal (GI) tract is composed of a diverse set of organs that together receive extracorporeal nutrition and convert it to energy substrates and cellular building blocks. In the process, it must sort through all that we ingest and discriminate what is useable from what is not, and having done that, it discards what is "junk." To accomplish these many and varied tasks, the GI tract relies on endogenous enteric hormones produced by enteroendocrine cells and the enteric nervous system. In many instances, the mediators of these tasks are small peptides that home to the CNS and accessory gut organs to coordinate oral intake with digestive secretions. As the contents of ingested material can contain harmful agents, the gut is armed with an extensive immune system. A breach of the epithelial barrier of the GI tract can result in local and eventually systemic disease if the gut does not mount an aggressive immune response.
\end{abstract}

The adult luminal gastrointestinal (GI) tract is a mesoderm-derived muscular tube lined with specialized epithelium that extends from the posterior pharynx (the point at the back of the throat where the respiratory tract and GI tract separate) to the anus. Accessory organs such as the liver, pancreas, and gallbladder are appended to what is a nearly 20 -foot tube in humans, having arisen initially as outpouchings of the embryonic foregut (Figure 1). The embryonic foregut forms from visceral endoderm at about day 22 in the human (day 9 in the mouse) and is encased in mesoderm that eventually becomes the circular and longitudinal smooth muscles needed for peristalsis (1). Both the respiratory tract and the luminal GI tract arise from the foregut tube and are parallel tubular structures lined with endoderm (1). Throughout development, and into adulthood, the respiratory and GI tracts share a common anterior chamber, the pharynx. Epithelial outpouchings from the developing pharynx emerge to form endocrine and lymphoid tissues, including the tonsils, thyroid, thymus, and parathyroid glands (1). Regional specialization occurs once the digestive tube constricts to form the esophagus and sequentially more distal portions of the luminal GI tract, that is, the stomach, and small and large intestines. Both the extreme anterior and posterior ends of the visceral endoderm merge with ectoderm to become the oral palate (roof of the mouth) and anus, respectively.

It is widely believed that the collective organs of the GI tract merely function to receive, digest, absorb, and eliminate ingested substances. However, what lurks beneath this assortment of diverse organs is a highly sophisticated organ system that serves multiple automated functions. To accomplish these tasks, the GI tract coordinates the largest collection of endocrine and immune cells in the body $(2,3)$. The enteric nervous system is the second largest collection of neural cell bodies after the CNS (4). Disorders of the GI tract are therefore quite diverse and can result from altered homeostasis of each of these GI tract components. Like other bar-

Nonstandard abbreviations used: bHLH, basic helix-loop-helix; CRF, corticotropinreleasing factor; GI, gastrointestinal; GIST, GI stromal tumor.

Conflict of interest: The author has declared that no conflict of interest exists. Citation for this article: J. Clin. Invest. 117:6-12 (2007). doi:10.1172/JCI30974. rier surfaces (such as the skin and respiratory tracts), the gut has forged a symbiotic relationship with numerous microorganisms, which reside at their highest concentrations in the oral cavity and colon (5). However, perturbation of normal microbial-epithelial interactions contributes to a range of disorders that can result in bacterial infections (e.g., Escherichia coli O157 and Tropheryma whipplei) or autoimmune disorders (e.g., Crohn disease and pernicious anemia). In the former example, invading microorganisms overwhelm the immune system, whereas in the latter, the microbially activated immune response is not contained and causes tissue injury. Malabsorption has long been studied as a mechanism underlying malnutrition and growth retardation in developing countries and underserved populations in the United States. However, the epidemic that is now sweeping wealthier nations is the disease of abundance and "overabsorption." Although research in this area has traditionally focused on the adipocyte (6-9), renewed interest in regulating oral input has stimulated investigation into the afferent hormonal and neural circuitry that controls appetite and blood sugar, and how dysregulation of endocrine and neural homeostasis in the GI tract might contribute to obesity.

The 7 articles in this Review Series on Gastrointestinal Homeostasis and Disease discuss different ways in which the endocrine, neural, and immune components of the GI tract regulate GI function in these 2 conditions (Figure 2). The role of neural brain-gut circuits and gut hormones in the control of food intake and blood glucose will be covered in the first 2 articles. Therapeutic targets of the enteric nervous system to treat functional bowel disorders are discussed in the third. Finally, perturbation of the immune system by various exogenous signals is the common theme that links the remaining 4 articles.

\section{Neuroendocrine control of energy homeostasis: feast or famine}

Several minutes before we see our meal, the aroma of food sends signals to our gut to prepare for the feast by increasing digestive juices filled with gastric acid and intestinal digestive enzymes. Likewise, audible gut peristalsis (borborygmi) percolates up to our consciousness and informs our brain that we need food. Both are 


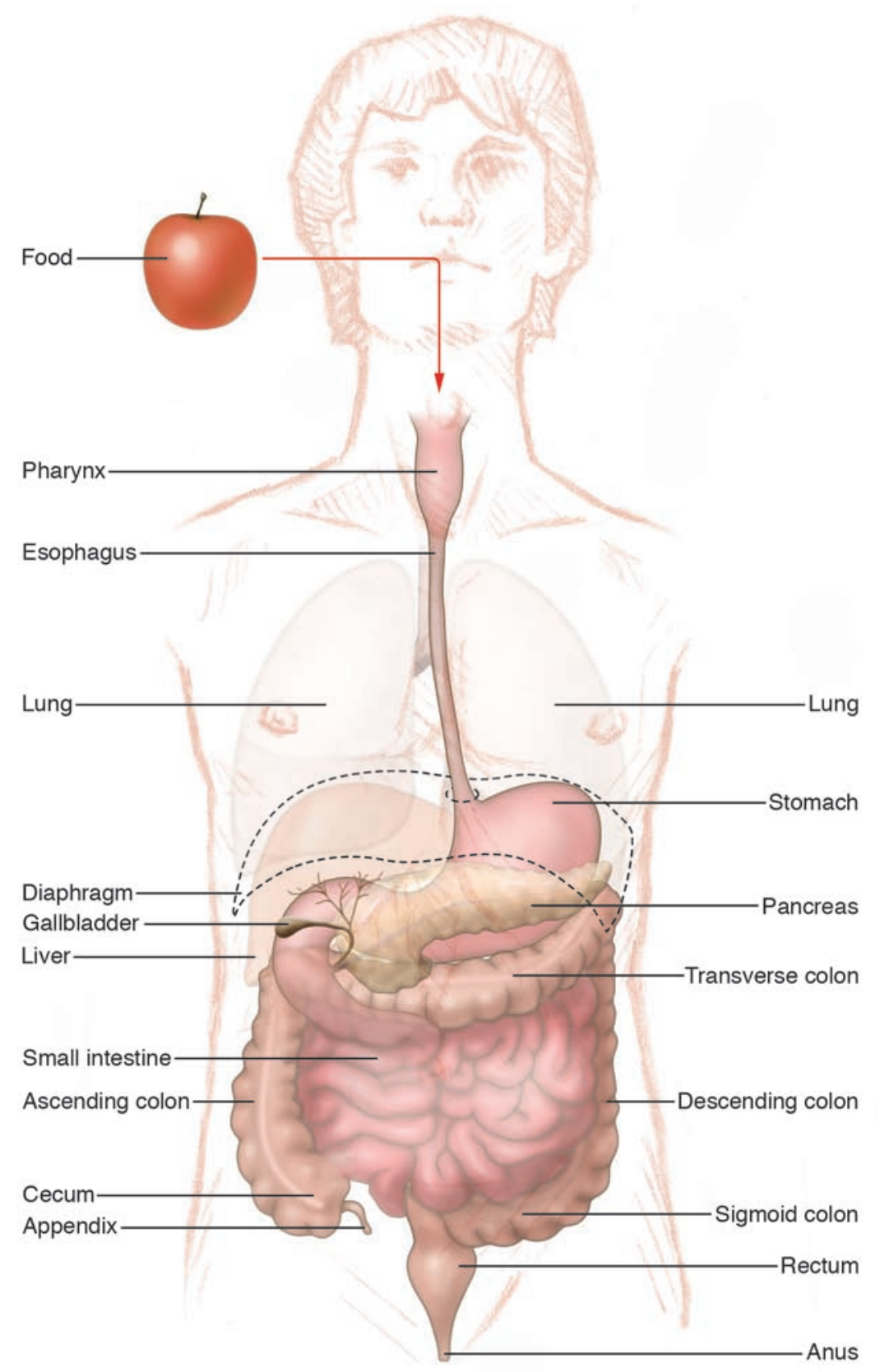

\section{Figure 1}

Overview of the Gl tract. In humans, the Gl tract is a 20-foot muscular tube lined with primarily endodermally derived columnar epithelial cells. The esophagus begins at the end of the posterior pharynx. The esophagus courses through the thoracic cavity and pierces the diaphragm, where it enters the abdominal cavity and merges with the stomach. The stomach merges distally with the small intestine, which is divided into 3 parts, the duodenum, jejunum, and ileum. The terminal ileum joins the colon at the ileocecal valve. The colon begins in the right lower abdomen (ascending colon) and transverses under the liver into the transverse, then left, colon. Just before entering the rectum, the distal left colon forms an $\mathrm{S}$ shape (the sigmoid colon). The luminal GI tract ends at the anus. The liver, pancreas, and gallbladder are accessory organs that form as appendages from the second portion of the duodenum. examples of brain-gut pathways that are coordinated by a careful mix of neurotransmitters and peptide hormones. Normal gut regulation of energy sources requires cooperation between the enteric nervous system and mucosa-based peptides. Ignoring the normal signals has contributed to obesity and diabetes. Therefore, both the identification and the manipulation of these pathways have become the focus of intense study.

Appetite control: "Just say no!" The obesity epidemic in this country has re-energized scientific interest in how appetite and food intake is controlled. Although adipocyte-generated leptin was the first of the new wave of regulatory peptides to be genetically linked to obesity $(10,11)$, several other peptides have been recently discovered and linked to appetite control. The most prominent has been the somatotrophic peptide ghrelin. Since its discovery in 1999 $(12,13)$, there have been nearly 2,000 articles published about ghre- lin (as determined by a Medline search for ghrelin). A 28-amino acid peptide made in high concentrations in the gastric corpus, ghrelin opposes the satiety signal leptin by serving as an afferent orexigenic signal to the hypothalamus $(14,15)$. In normal healthy individuals, a fasting stomach triggers ghrelin release. By contrast, constitutively elevated levels of ghrelin cause individuals to suffer from an extreme form of excessive appetite and obesity known as Prader-Willi syndrome (16). The first article in the Review Series, by David Cummings and Joost Overduin, summarizes the contributions from both neural sensory afferents and enteroendocrine hormones in the regulation of food intake (17).

The gut and glucose homeostasis. For decades, the control of blood sugar has been considered the purview of the pancreatic islets of Langerhans, because they contain endocrine cells producing insulin and glucagon. As a result, treatments for diabetes have centered 


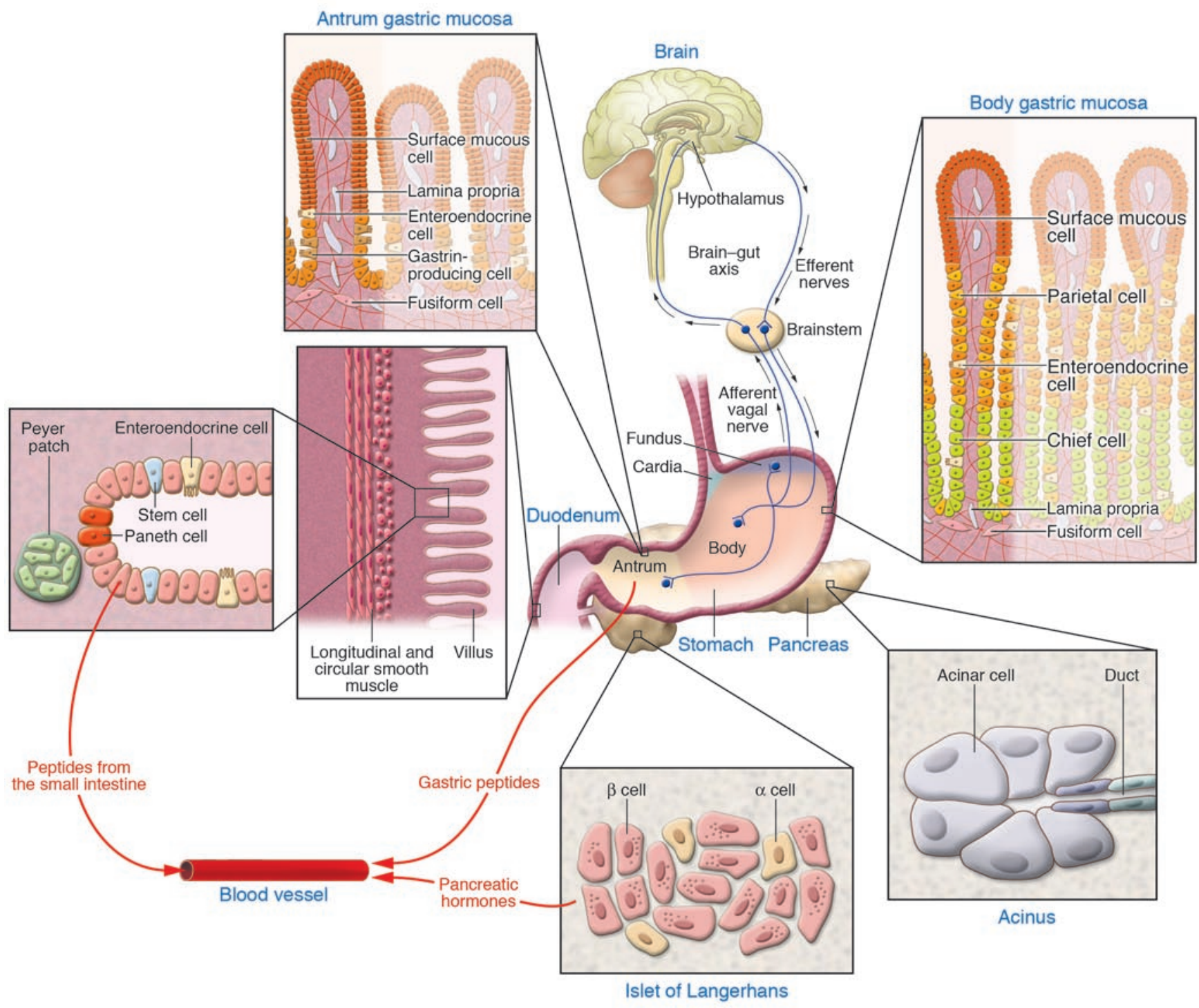

\section{Figure 2}

Components of the neural, endocrine, and immune systems that regulate Gl function. Essential components discussed in this overview are shown. Vagal afferents emerge from the ganglia between the layers of smooth muscle (circular and longitudinal) surrounding the stomach and small intestine to synapse in the spinal cord and brain (collectively the CNS). In addition, the brain (especially the hypothalamus) relays efferent signals to target organs. The human stomach is divided into 4 regions (cardia, fundus, body [corpus], and antrum). The acid-secreting parietal cells are found in the corpus, whereas the gastrin-producing cells are found in the antrum. Neuroendocrine cells secrete gastric peptides such as ghrelin in the corpus and gastrin in the antrum into the circulation through local capillaries. Similarly, regulatory peptides from neuroendocrine cells in the small intestine and pancreatic islets of Langerhans are secreted into the bloodstream. Collections of immune cells are most prominent in the small intestine as Peyer patches. In addition, the Paneth cells at the base of the intestinal crypts secrete antimicrobial peptides including lysozyme and defensins. Stem cells in the small intestine are anatomically well defined as the 4th cell from the base of the crypt.

exclusively on islet cell growth, regulation, or replacement (18-20). However, it has become apparent that peptides produced in the luminal GI tract (in particular, the stomach and proximal small intestine) influence $\beta$ cell growth and function. In this Review Series, Daniel Drucker discusses the incretin peptides secreted from the distal stomach and proximal small intestine (21). Glucagon-derived peptide-1 (GLP1) and glucose-dependent insulinotropic peptide (GIP) regulate blood glucose levels by stimulating insulin release and facilitating glucose uptake by peripheral tissues (22). As with many regulatory peptides, generation of the active peptide from pro-forms and their subsequent inactivation is mediated by tissue peptidases. As Drucker reviews, these peptidases are an important therapeutic target that, when inhibited, can sustain insulin levels and reduce blood sugar $(23,24)$.

Many consider the stomach as a receptive, capacitance vessel or muscular "holding tank" available merely to receive a meal, begin digestion by treating its contents with hydrochloric acid and then grinding the resulting chyme into small bits for easy digestion in the small intestine. Yet, as the Reviews by Cummings and Overduin (17) and Drucker (21) suggest, the gastric body 
and antrum are emerging as important sources of regulatory peptides that control metabolism through the brain-gut axis and at peripheral tissues. Expression of many of these peptides that can regulate metabolism overlaps in a region of the proximal intestine also known clinically as the "gastrinoma triangle" because it is frequently the site of endocrine tumors known as gastrinomas (25). Lineage-tracing experiments demonstrate that the endocrine cells of the gastric antrum are closely related to the endocrine cells in the duodenum, which in turn share features of pancreatic islet cells (26). Indeed, the endocrine cells in these tissues seem to be developmental remnants from the period of early gut specialization when the pancreas budded off from the foregut tube near the border between the gastric antrum and the duodenum. The basic helix-loop-helix (bHLH) transcription factor pancreatic and duodenal homeobox gene 1 (PDX1), which is essential for pancreatic development, also regulates the expression of peptides in the proximal duodenum and antrum (27-29), further reinforcing the developmental link between cells in the luminal GI tract and pancreas. Recently, it has been shown that another bHLH transcription factor, neurogenin-3, is required for both pancreatic $\beta$ cell development $(30,31)$ and enteroendocrine cell development (32). Humans born with mutations in the DNA-binding domain of neurogenin-3 fail to develop all enteroendocrine cells and exhibit chronic diarrhea despite normal numbers and function of enterocytes (32). Older subjects that harbor these mutations exhibit hyperglycemia (32). Therefore, mutations in the gene encoding neurogenin-3 might underlie a form of maturity-onset diabetes of the young. Some individuals who are heterozygous for these mutations might exhibit milder forms of chronic diarrhea, and this could be one cause of diarrhea-predominant functional bowel disorders.

\section{Neural control of GI function: gut trumps brain}

Gut instincts. For centuries, the ability to sense danger or the true intentions of lovers, friends, and foes has been attributed to one's "gut instincts." What is it about the tranquil, imperceptible movements of the gut that signal that all is well with us and our environment? Compare this with the violent roiling of the intestines when we are nervous, fearful, or apprehensive. Deep within our body cavity, these automated movements relay signals to the CNS that frequently override rational thought and reason. Unfortunately for millions of individuals, these dyspeptic symptoms physically manifest themselves as embarrassing (diarrhea) or painful (constipation) episodes of altered GI visceral sensitivity. In the absence of structural abnormalities, the dyspeptic symptoms are categorized as functional bowel disorders (33). Two-thirds of patients who have symptoms of functional bowel disorders are women, which suggests some etiologic contribution from female sex hormones (34). In addition, patients with severe bouts of infectious diarrhea tend to develop chronic dyspepsia $(35,36)$. This observation has suggested a role for proinflammatory cytokines in either the initiation or the persistence of functional bowel disorders (37-39). However, the major focus of research has been on the role of the brain-gut circuit that is mediated by both circulating neuropeptides and neurotransmitters $(40,41)$. In this Review Series, Yvette Taché and Bruno Bonaz concentrate on neuropeptide control of the brain-gut circuit and on the role of the hypothalamic peptide corticotropin-releasing factor (CRF) in particular (42). Since a frequent trigger of dyspeptic symptoms in patients with functional bowel disorders is stress, and increased CRF release has been shown to be a component of the acute stress response, CRF antagonists are actively being developed for the treatment of functional bowel disorders, as well as other stress-induced disorders.

\section{Innate immune defenses: a sleeping giant awakes}

Perhaps underappreciated by many is the fact that the largest source of immune cells in the body is the GI tract (3). As a result, several chronic GI disorders are actually due to an aggressive assault by the innate immune system. The last 4 articles in this Review Series focus on different immune-mediated GI disorders. Although not generally considered classic regulatory peptides, proinflammatory cytokines released from either mucosa-based or circulating lymphocytes are critical to maintaining GI tract defenses.

Celiac disease: let them eat cake? Nearly $1 \%$ of the United States population (approximately 3 million individuals) suffer from some form of celiac disease (43). Yet, improved knowledge of its immunopathogenesis has not altered treatment for the disease, nor has it lead to any treatments for the rare complications of celiac disease, that is, enteropathy-associated $\mathrm{T}$ cell lymphomas and adenocarcinomas. Although initially considered a rare disorder with a prevalence as low as 1 in 8,000 , celiac disease is now known to be relatively common ( 1 in 250 individuals in the United States suffers from celiac disease) $(44,45)$. Its protean clinical presentation ranges from asymptomatic to unexplained iron deficiency anemia to full-blown classical symptoms of weight loss, malabsorption, and steatorrhea. Asymptomatic and mild cases are now more frequently detected, because of improved serologic diagnostics based on the knowledge that the ingested proteins that cause celiac disease, and the enzymatic system that renders the peptides antigenic, induce a specific subset of IgA antibodies. Proteins of common cereal grains, collectively called glutens, interact with the MHC class II heterodimer HLA-DQ2 and are displayed on the surface of APCs. In this Review Series, Martin Kagnoff describes how grain-derived proteins that are deamidated by tissue transglutaminase then activate the innate immune system (46). What remains an enigma is how the $H L A-D Q 2$ locus and other undetermined loci render the gut more susceptible to activation by the innate immune response, with subsequent production of proinflammatory cytokines (such as IFN- $\gamma$ ), simply from ingestion of these proteins. As a result of improved diagnostic testing, treatment is specific and cheap, though not necessarily easy to implement or tolerate: imagine a diet without any wheat, rye, or barley! The need to eschew traditional bakery breads, cakes, cookies, and pastas, to mention but a few of the common foods that must be avoided, is clearly not simple and is the basis for frequent accidental or intentional noncompliance (47). The frequent lapses in compliance are a major reason to understand the pathophysiology of celiac disease and develop targeted therapies. Although, on the surface, the search for additional therapies might seem to be merely a matter of "taste," over time, noncompliance increases susceptibility to intestinal cancers (48).

The "stars" of the pancreas. Cirrhosis of the liver and chronic pancreatitis, disorders of excessive tissue fibrosis, collectively are responsible for a substantial percentage of morbidity and mortality from alcohol use. Parenchymal organs such as the liver, kidney, and pancreas respond to injury by becoming fibrotic. Initially because of work in the liver, the stellate (star-shaped) cells in these organs were found to be the source of the fibrosis. Although overshadowed by more numerous studies on the hepatic stellate 
cell $(49,50)$, it is now recognized that the pancreatic stellate cell is responsible for the fibrotic changes that occur in this organ, and this is the focus of the Review Series article by Bishr Omary and colleagues (51). In both the liver and the pancreas, activation of these stellate cells can overwhelm the entire organ, resulting initially in reduced phenotypic functions, for example, liver detoxification and pancreatic enzyme production. Chronic injury, inflammation, and fibrosis lead to tumor formation in subjects with cirrhosis or chronic pancreatitis. The sequence of events is not unlike the response of other tissues to chronic irritation in which sustained wound-healing reactions are activated (52-54). Proinflammatory cytokines generated in response to toxins, usually alcohol, stimulate the stellate cells to produce fibrillary proteins. Subsequently, the stellate cells sustain their activated state by producing autocrine factors. Presumably, these factors accelerate fibrosis and chronically stimulate neoplastic transformation in the pancreatic duct. This scenario suggests a synergistic relationship between the stellate cell and the cellular precursors of cancer, for example, stem cells (55-57). Given this synergistic relationship, it is interesting that most hepatic stellate cells arise from the bone marrow, a fact that might also hold true for the pancreatic stellate cell (58). Gene expression profile comparisons between hepatic and pancreatic stellate cells (microarrays) have confirmed the strong phenotypic similarity of these cells despite their residence in different tissues (59), providing further evidence to support the speculation that pancreatic stellate cells also arise from hematopoietic precursors. A link between stem cells in the bone marrow and cancer is a concept that has also been observed for gastric cancer (60), and this link is discussed further in this Review Series by James Fox and Timothy Wang (61).

"Bugs in the belfry": gastric cancer as a chronic immune disorder. In the early 1900s, cancer of the distal stomach was the leading cause of death from cancer in the United States. Seventy years later, gastric cancer has declined to about the 10th leading cause of death from cancer in the United States, but it is still ranked second worldwide. Improvements in food storage and public sanitation are considered the major reasons for the decline in these statistics (reviewed in ref. 62), suggesting that this is a disease that can be prevented. In 1994, the association of gastric cancer with Helicobacter pylori revealed that cellular transformation in the stomach, like chronic injury in other tissues, is also linked to chronic inflammation (63). It was known before the H. pylori connection was established that pernicious anemia, due to parietal cell destruction by autoantibodies specific for parietal cell proteins, was the only specific disorder linking gastric cancer to chronic inflammation (64). In this disorder, immune-mediated destruction of acid-secreting parietal cells prevents the dietary absorption of vitamin B12, because intrinsic factor (which is required for vitamin B12 absorption) is synthesized by the parietal cell. In a 1975 Lancet article (65), Pelayo Correa described the histologic changes leading to intestinal-type gastric cancer. In that report, loss of gastric parietal and chief cells was documented as a crucial step in the progression of the mucosa toward transformation. In this Review Series, Fox and Wang reiterate this point and make a clear distinction between the intermediate steps (atrophy and metaplasia) that lie between chronic inflammation and commitment of the mucosa to irreversible neoplastic changes, that is, dysplasia (61). Apparently, loss of specific cell types (atrophy) is a more consistent indicator of transformation than gain of replacement cells of gastric or intestinal mucous cell origin (metaplasia)
(66). Therefore, with respect to intervening in the progression toward gastric cancer, there are 2 key steps - prevent inflammation and/or prevent atrophy. Given the number of cancers caused by chronic inflammation (67-71), an understanding of progression in the stomach will probably have broad applicability.

Taking aim: receptors of regulatory peptides and cytokines as therapeutic targets. The molecular mechanisms responsible for 2 rare disorders, Ménétrier disease and GI stromal tumors (GISTs), are constitutive activation of distinct cytokine and growth factor receptors, respectively. Ménétrier disease is caused by EGFR-mediated expansion of the surface mucous cell layer in the stomach. A consequence of this expansion is the displacement and subsequent loss of parietal and chief cells, a process that is also observed in the progression toward gastric cancer. However, unlike gastric cancer triggered by $H$. pylori-mediated gastritis, Ménétrier disease develops because the upper third of the gastric gland expands. The histologic features of Ménétrier disease have been recapitulated with the use of a transgenic mouse overexpressing TGF- $\alpha$ and revealed a substantial etiologic contribution from EGFR activation (72). Nevertheless, in human subjects, the reason why this particular portion of the gland proliferates is not known; it might be due to an infectious agent. For example, the childhood form of Ménétrier disease is observed after infection with CMV (73), raising the possibility that an infectious agent might be responsible for the hypertrophic gastric folds in adults (74). If the phenotypic hypertrophic folds are observed in adults after infection with a virus or other infectious agent, then this seemingly rare disorder actually might be more common. In particular, $H$. pylori seems to be a probable infectious agent in adults with Ménétrier disease $(75,76)$. Chronic infection with Helicobacter spp. in mice is associated with elevated levels of EGFR ligands (77). Moreover, treatment with a blocking $\mathrm{mAb}$ specific for EGFR, cetuximab, has been shown to be efficacious in suppressing the persistent nausea and vomiting in a patient with Ménétrier disease (78).

By contrast, GISTs are tumors arising in the submucosa of the GI tract because of constitutively activating mutations in either PDGFRA or KIT on the interstitial cells of Cajal. KIT binds SCF and is also expressed by hematopoietic progenitors, mast cells, and germ cells. PDGFRA and KIT are members of the hematopoietic class III receptor tyrosine kinase family that contain Ig motifs and signal through MAPK and AKT pathways (79). As a result, specific molecular therapies targeting the tyrosine kinase domain of PDGFRA and KIT, which were initially developed to treat certain types of leukemia, have proven to be clinically useful and superior to chemotherapy and surgery for the treatment of GISTs, although they are not curative.

Application of knowledge about how these cytokine and growth factor receptors cause these specific diseases has led to the development of therapies for these 2 gastric disorders and is the focal point of the final article in this Review Series, by Robert Coffey and colleagues (80).

\section{Acknowledgments}

This work was supported by NIH grants P01 DK062041 and R01 DK061410.

Address correspondence to: Juanita L. Merchant, 109 Zina Pitcher Place, 2051 Basic Science Research Building, Ann Arbor, Michigan 48109-2200, USA. Phone: (734) 647-2944; Fax: (734) 763-4686; E-mail: merchanj@umich.edu. 
1. Gilbert, S.F. 1994. Developmental biology. Sinauer Associates Inc. Sunderland, Massachusetts, USA 361-368.

2. Ahlman, H., and Nilsson. 2001. The gut as the largest endocrine organ in the body. Ann. Oncol. 12(Suppl. 2):S63-S68.

3. Kelly, D., and Coutts, A.G. 2000. Early nutrition and the development of immune function in the neonate. Proc. Nutr. Soc. 59:177-185.

4. Goyal, R.K., and Hirano, I. 1996. The enteric nervous system. N. Engl. J. Med. 334:1106-1115.

5. Wilson, K.H. 1999. The gastrointestinal biota. In Textbook of gastroenterology. T. Yamada, D.H. Alpers, L. Laine, C. Owyang, and D. Powell, editors. Lippincott Williams \& Wilkins. Philadelphia, Pennsylvania, USA. 624-636.

6. Cecil, J.E., Watt, P., Palmer, C.N., and Hetherington, M. 2006. Energy balance and food intake: the role of PPARgamma gene polymorphisms. Physiol. Behav. 88:227-233.

7. Langin, D. 2006. Adipose tissue lipolysis as a metabolic pathway to define pharmacological strategies against obesity and the metabolic syndrome. Pharmacol. Res. 53:482-491.

8. Jackson, M.B., and Ahima, R.S. 2006. Neuroendocrine and metabolic effects of adipocyte-derived hormones. Clin. Sci. (Lond.) 110:143-152.

9. Bluher, M. 2005. Transgenic animal models for the study of adipose tissue biology. Best Pract. Res. Clin. Endocrinol. Metab. 19:605-623.

10. Zhang, Y., et al. 1994. Positional cloning of the mouse obese gene and its human homologue. Nature. 372:425-431.

11. Campfield, L.A., Smith, F.J., Guisez, Y., Devos, R., and Burn, P. 1995. Recombinant mouse OB protein: evidence for a peripheral signal linking adiposity and central neural networks. Science. 269:546-549.

12. Kojima, M., et al. 1999. Ghrelin is a growth-hormone-releasing acylated peptide from stomach. Nature. 402:656-660.

13. Kojima, M., and Kangawa, K. 2005. Ghrelin: structure and function. Physiol. Rev. 85:495-522.

14. Wortley, K.E., et al. 2005. Absence of ghrelin protects against early-onset obesity. J. Clin. Invest. 115:3573-3578. doi:10.1172/JCI26003.

15. Wortley, K.E., et al. 2004. Genetic deletion of ghrelin does not decrease food intake but influences metabolic fuel preference. Proc. Natl. Acad. Sci. U. S. A 101:8227-8232.

16. Cummings, D.E., et al. 2002. Elevated plasma ghrelin levels in Prader Willi syndrome. Nat. Med. 8:643-644.

17. Cummings, D.E., and Overduin, J. 2007. Gastrointestinal regulation of food intake. J. Clin. Invest. 117:13-23. doi:10.1172/JCI30227.

18. Wong, V.S., and Brubaker, P.L. 2006. From cradle to grave: pancreatic beta-cell mass and glucagonlike peptide-1. Minerva Endocrinol. 31:107-124.

19. Heit, J.J., et al. 2006. Calcineurin/NFAT signalling regulates pancreatic beta-cell growth and function. Nature. 443:345-349.

20. Shapiro, A.M., et al. 2006. International trial of the Edmonton protocol for islet transplantation. N. Engl. J. Med. 355:1318-1330.

21. Drucker, D.J. 2007. The role of gut hormones in glucose homeostasis. J. Clin. Invest. 117:24-32. doi:10.1172/JCI30076.

22. Rendell, M.S., and Jovanovic, L. 2006. Targeting postprandial hyperglycemia. Metabolism. 55:1263-1281.

23. Triplitt, C., Wright, A., and Chiquette, E. 2006. Incretin mimetics and dipeptidyl peptidase-IV inhibitors: potential new therapies for type 2 diabetes mellitus. Pharmacotherapy. 26:360-374.

24. Gallwitz, B. 2005. Glucagon-like peptide-1-based therapies for the treatment of type 2 diabetes mellitus. Treat. Endocrinol. 4:361-370.
25. Kaplan, E.L., et al. 1990. Gastrinomas: a 42-year experience. World J. Surg. 14:365-375; discussion 375-376.

26. Schonhoff, S.E., Giel-Moloney, M., and Leiter, A.B. 2004. Neurogenin 3-expressing progenitor cells in the gastrointestinal tract differentiate into both endocrine and non-endocrine cell types. Dev. Biol. 270:443-454

27. Lee, C.S., Perreault, N., Brestelli, J.E., and Kaestner, K.H. 2002. Neurogenin 3 is essential for the proper specification of gastric enteroendocrine cells and the maintenance of gastric epithelial cell identity. Genes Dev. 16:1488-1497.

28. Larsson, L.I., Madsen, O.D., Serup, P., Jonsson, J., and Edlund, H. 1996. Pancreatic-duodenal homeobox 1: role in gastric endocrine patterning. Mech. Dev. 60:175-184.

29. Nomura, S., et al. 2005. Evidence for repatterning of the gastric fundic epithelium associated with Ménétrier's disease and TGFalpha overexpression. Gastroenterology. 128:1292-1305.

30. Huang, H.P., et al. 2000. Regulation of the pancreatic islet-specific gene BETA2 (neuroD) by neurogenin 3. Mol. Cell. Biol. 20:3292-3307.

31. Habener, J.F., Kemp, D.M., and Thomas, M.K. 2005. Minireview: transcriptional regulation in pancreatic development. Endocrinology. 146:1025-1034.

32. Wang, J., et al. 2006. Mutant neurogenin-3 in congenital malabsorptive diarrhea. N. Engl. J. Med. 355:270-280

33. Talley, N.J. 2006. Irritable bowel syndrome. Intern. Med. J. 36:724-728.

34. Mayer, E.A., Naliboff, B., Lee, O., Munakata, J., and Chang, L. 1999. Review article: gender-related differences in functional gastrointestinal disorders. Aliment. Pharmacol. Ther. 13(Suppl. 2):65-69.

35. Stermer, E., Lubezky, A., Potasman, I., Paster, E., and Lavy, A. 2006. Is traveler's diarrhea a significant risk factor for the development of irritable bowel syndrome? A prospective study. Clin. Infect. Dis. 43:898-901.

36. Halvorson, H.A., Schlett, C.D., and Riddle, M.S. 2006. Postinfectious irritable bowel syndrome: a meta-analysis. Am. J. Gastroenterol. 101:1894-1899; quiz 1942.

37. Collins, S.M. 2005. Dysregulation of peripheral cytokine production in irritable bowel syndrome. Am. J. Gastroenterol. 100:2517-2518.

38. Riordan, S.M., and Kim, R. 2006. Bacterial overgrowth as a cause of irritable bowel syndrome. Curr. Opin. Gastroenterol. 22:669-673.

39. Dinan, T.G., et al. 2006. Hypothalamic-pituitarygut axis dysregulation in irritable bowel syndrome: plasma cytokines as a potential biomarker? Gastroenterology. 130:304-311.

40. Bhatia, V., and Tandon, R.K. 2005. Stress and the gastrointestinal tract. J. Gastroenterol. Hepatol. 20:332-339.

41. Andresen, V., and Camilleri, M. 2006. Irritable bowel syndrome: recent and novel therapeutic approaches. Drugs. 66:1073-1088.

42. Taché, Y., and Bonaz, B. 2007. Corticotropin-releasing factor receptors and stress-related alterations of gut motor function. J. Clin. Invest. 117:33-40. doi:10.1172/JCI30085.

43. Lee, S.K., and Green, P.H. 2006. Celiac sprue (the great modern-day imposter). Curr. Opin. Rheumatol. 18:101-107.

44. Lewis, N.R., and Scott, B.B. 2006. Systematic review: the use of serology to exclude or diagnose coeliac disease (a comparison of the endomysial and tissue transglutaminase antibody tests). Aliment. Pharmacol. Ther. 24:47-54.

45. Fasano, A., et al. 2003. Prevalence of celiac disease in at-risk and not-at-risk groups in the United States: a large multicenter study. Arch. Intern. Med. 163:286-292.
46. Kagnoff, M.F. 2007. Celiac disease: pathogenesis of a model immunogenetic disease. J. Clin. Invest. 117:41-49. doi:10.1172/JCI30253.

47. See, J., and Murray, J.A. 2006. Gluten-free diet: the medical and nutrition management of celiac disease. Nutr. Clin. Pract. 21:1-15.

48. Brousse, N., and Meijer, J.W. 2005. Malignant complications of coeliac disease. Best Pract. Res. Clin. Gastroenterol. 19:401-412.

49. Kisseleva, T., and Brenner, D.A. 2006. Hepatic stellate cells and the reversal of fibrosis. J. Gastroenterol. Hepatol. 21(Suppl. 3):S84-S87.

50. Friedman, S.L. 2006. Transcriptional regulation of stellate cell activation. J. Gastroenterol. Hepatol. 21(Suppl. 3):S79-S83.

51. Omary, M.B., Lugea, A., Lowe, A.W., and Pandol, S.J. 2007. The pancreatic stellate cell: a star on the rise in pancreatic diseases. J. Clin. Invest. 117:50-59. doi:10.1172/JCI30082.

52. Demetris, A.J., Lunz, J.G., 3rd, Specht, S., and Nozaki, I. 2006. Biliary wound healing, ductular reactions, and IL-6/gp130 signaling in the development of liver disease. World J. Gastroenterol. 12:3512-3522.

53. Giannelli, G., Quaranta, V., and Antonaci, S. 2003. Tissue remodelling in liver diseases. Histol. Histopathol. 18:1267-1274.

54. Dalgleish, A.G., and O'Byrne, K. 2006. Inflammation and cancer: the role of the immune response and angiogenesis. Cancer Treat. Res. 130:1-38.

55. Direkze, N.C., and Alison, M.R. 2007. Bone marrow and tumour stroma: an intimate relationship. Hematol. Oncol. In press.

56. Tan, B.T., Park, C.Y., Ailles, L.E., and Weissman, I.L. 2006. The cancer stem cell hypothesis: a work in progress. Lab. Invest. 86:1203-1207.

57. Tataria, M., Perryman, S.V., and Sylvester, K.G. 2006. Stem cells: tissue regeneration and cancer. Semin. Pediatr. Surg. 15:284-292.

58. Russo, F.P., et al. 2006. The bone marrow functionally contributes to liver fibrosis. Gastroenterology. 130:1807-1821.

59. Buchholz, M., et al. 2005. Transcriptome analysis of human hepatic and pancreatic stellate cells: organ-specific variations of a common transcriptional phenotype. J. Mol. Med. 83:795-805.

60. Houghton, J., et al. 2004. Gastric cancer originating from bone marrow-derived cells. Science. 306:1568-1571.

61. Fox, J.G., and Wang, T.C. 2007. Inflammation, atrophy, and gastric cancer. J. Clin. Invest. 117:60-69. doi:10.1172/JCI30111.

62. Merchant, J.L. 2005. Inflammation, atrophy, gastric cancer: connecting the molecular dots. Gastroenterology. 129:1079-1082.

63. Blaser, M.J., and Parsonnet, J. 1994. Parasitism by the "slow" bacterium Helicobacter pylori leads to altered gastric homeostasis and neoplasia. J. Clin. Invest. 94:4-8.

64. Hsing, A.W., et al. 1993. Pernicious anemia and subsequent cancer. A population-based cohort study. Cancer. 71:745-750.

65. Correa, P., Haenszel, W., Cuello, C., Tannenbaum, S., and Archer, M. 1975. A model for gastric cancer epidemiology. Lancet. 2:58-60.

66. El-Zimaity, H.M., Ota, H., Graham, D.Y., Akamatsu, T., and Katsuyama, T. 2002. Patterns of gastric atrophy in intestinal type gastric carcinoma. Cancer. 94:1428-1436.

67. Cormier, J.N., and Vauthey, J.N. 2000. Biliary tract cancer. Curr. Opin. Gastroenterol. 16:437-443.

68. Prinz, C., Schwendy, S., and Voland, P. 2006. H pylori and gastric cancer: shifting the global burden. World J. Gastroenterol. 12:5458-5464.

69. Itzkowitz, S.H. 2006. Molecular biology of dysplasia and cancer in inflammatory bowel disease. Gastroenterol. Clin. North Am. 35:553-571.

70. MacLennan, G.T., et al. 2006. The influence of 
chronic inflammation in prostatic carcinogenesis: a 5-year followup study. J. Urol. 176:1012-1016.

71. Aggarwal, B.B., Shishodia, S., Sandur, S.K., Pandey, M.K., and Sethi, G. 2006. Inflammation and cancer: how hot is the link? Biochem. Pharmacol. 72:1605-1621.

72. Sharp, R., et al. 1995. Transforming growth factor $\alpha$ disrupts the normal program of cellular differentiation in the gastric mucosa of transgenic mice. Development. 121:149-161.

73. Hochman, J.A., Witte, D.P., and Cohen, M.B. 1996. Diagnosis of cytomegalovirus infection in pediatric Ménétrier's disease by in situ hybridization. J. Clin. Microbiol. 34:2588-2589.
74. Xiao, S.Y., and Hart, J. 2001. Marked gastric foveolar hyperplasia associated with active cytomegalovirus infection. Am. J. Gastroenterol. 96:223-226.

75. Watanabe, K., Beinborn, M., Nagamatsu, S., Ishida, H., and Takahashi, S. 2005. Ménétrier's disease in a patient with Helicobacter pylori infection is linked to elevated glucagon-like peptide-2 activity. Scand. J. Gastroenterol. 40:477-481.

76. Madisch, A., et al. 2004. Resolution of gastrointestinal protein loss after Helicobacter pylori eradication in a patient with hypertrophic lymphocytic gastritis. Helicobacter. 9:629-631.

77. Wang, T.C., et al. 2000. Synergistic interaction between hypergastrinemia and Helicobacter infection in a mouse model of gastric cancer. Gastroenterology. 118:36-47.

78. Burdick, J.S., et al. 2000. Treatment of Ménétrier's disease with a monoclonal antibody against the epidermal growth factor receptor. $N$. Engl. J. Med. 343:1697-1701.

79. Rosnet, O., and Birnbaum, D. 1993. Hematopoietic receptors of class III receptor-type tyrosine kinases. Crit. Rev. Oncog. 4:595-613.

80. Coffey, R.J., Washington, M.K., Corless, C.L., and Heinrich, M.C. 2007. Ménétrier disease and gastrointestinal stromal tumors: hyperproliferative disorders of the stomach. J. Clin. Invest. 117:70-80. doi:10.1172/JCI30491. 